\title{
Sociología
}

Campos Medina, F., Fonseca, F., \& Fuentes V.

(2019). Presentación del dossier: Conflictos socioambientales. Revista de Sociología, 34(1), 1-3. doi: 10.5354/0719-529X.2019.54272

\section{Presentación del dossier: Conflictos socioambientales}

\author{
Fernando Campos Medinaํㅡ, Francisca Fonseca ${ }^{2}$, \& Verónica Fuentes ${ }^{3}$ \\ ${ }^{1}$ Universidad de Chile; 2 Universidad de La Frontera; ${ }^{3}$ Universidad Austral de Chile
}

Nuestro interés por organizar un número especial de la Revista de Sociología sobre conflictos socioambientales partió a finales de 2018. Durante enero de este año iniciamos un extenso proceso de invitación a investigadoras e investigadores de habla hispana para publicar en este número. Para nuestra satisfacción, en poco tiempo tuvimos una respuesta auspiciosa. El resultado del proceso editorial que hoy, a fines de agosto de 2019, ponemos a disposición de la comunidad académica.

Mientras terminábamos los últimos detalles de este proceso, la Amazonía, el pulmón verde del planeta y nuestra gran reserva de biodiversidad para contener el aumento del $\mathrm{Co} 2$ en la atmósfera, arde fuera de control. Mientras observamos imágenes satelitales del incendio en el Amazonas, al otro lado del planeta, enormes secciones de antiguos glaciares se derrumban. Turistas deben abandonar rápidamente una playa rocosa en Islandia para ponerse a salvo y un par de kayakistas se encuentran cerca de perder la vida cuando intentan traspasar un puente de hielo, que cae inesperadamente a pocos metros de ellos. Durante este año 2019, en el hemisferio norte se registraron temperaturas veraniegas récord y las últimas inundaciones en la época lluviosa de Asia exhiben todo su potencial de devastación sobre poblaciones vulnerables.
En un tiempo extremadamente corto, finalizamos un proceso editorial que nos permite avanzar en nuestra comprensión acerca de las características, alcances y sentido de los conflictos socioambientales. Sin embargo, cualquier proceso editorial, por expedito que sea, parece incapaz de progresar a la velocidad de los desastres y conflictos socioambientales que afectan a nuestro planeta. La aceleración del cambio ambiental producido por la acción humana nos enseña no sólo un cambio cuantitativo -más episodios dramáticos por unidad de tiempo-, sino además, una transformación cualitativa en la forma en que como especie hemos vivido en relación a la naturaleza, al menos durante los últimos doscientos años. Este cambio supone que nuestras formas de vida social se ven radicalmente modificadas por aquello que, durante mucho tiempo, intentamos referir neutralmente como "entorno", "contexto", "mundo alrededor", "medioambiente", o "naturaleza".

La descripción moderna de la naturaleza como una entidad pasiva que podemos controlar y gestionar por medios artificiales parece sacudirnos y posicionarnos en una nueva etapa de la historia humana, marcada por la crisis climática, los conflictos socio-ambientales, la lucha por la adaptación y, lamentablemente aún, la mantención de formas insustentables de vida 
(Moore, 2016). Así, al presentar este número buscamos abrir la discusión sobre las capacidades de las ciencias sociales para dar cuenta de la crisis socioambiental que vivimos (Nixon, 2013).

Por mucho que la tradición crítica de las ciencias sociales se piense con la capacidad de comprender esta situación, ella no es menos producto de una sociedad basada en combustibles fósiles, que el mismo capitalismo que denuncia. En este sentido, todavía podemos sostener que, si en los orígenes de la sociología encontramos una crítica al orden social que aparece con la revolución industrial y la urbanización en el hemisferio norte, es desde el sur, en cuanto espacios coloniales, que aparece lo propiamente socioambiental en la reflexión de las ciencias sociales: por ejemplo, en la productiva ecología política latinoamericana (Alimonda, Toro Pérez \& Martín, 2017).

Para nosotras/os resulta inevitable que la crisis socioambiental y el aumento de los conflictos socioambientales tengan un efecto reorganizador sobre las ciencias sociales. A este respecto, creemos firmemente que las ciencias sociales deberán adaptar métodos y procesos investigativos para dar cuenta de la acelerada transformación socioambiental que nos toca vivir y que, de manera más dramática, afectará a las generaciones más jóvenes, aquellas a las que pertenecen nuestros hijos/as y estudiantes. A este respecto, algunos ejes interpretativos con los que queremos abrir esta conversación dicen relación con: i) una descripción flexible y abierta en relación a los casos de estudio; ii) visiones y usos críticos de las fuentes de información disponibles; iii) vinculación iterativa entre teoría e investigación empírica; iv) compromiso con los desafíos de una acción transformadora; y v) apertura investigativa al rol de las emociones en la producción de conocimiento.

Los artículos que ofrecemos en este número son todos reflejo de ello. En este sentido, tomando como base dos casos de estudio de proyectos energéticos, el artículo de Mauricio Cortéz nos propone observar los resultados políticos de los conflictos como el paso desde la preocupación socioambiental hacia lo socio-territorial. En una perspectiva complementaria, Mathilde Allain analiza de forma crítica la información disponible sobre protestas vinculadas a conflictos socioambientales, y desde allí observa quiénes y por qué se movilizan. Marcelo LeivaBianchi y colaboradores proponen el diseño y validación de una escala para la medición del impacto psicosocial de los desastres socionaturales. Este instrumento queda a disposición de futuras investigaciones para identificar respuestas disruptivas y saludables a los desastres que sin duda viviremos.

Cristián Parker y José Miguel Pérez proponen un marco teórico y metodológico para analizar el rol del conocimiento sociotécnico en los procesos de evaluación ambiental de grandes proyectos. Así, ellos reflexionan sobre la construcción social del conocimiento ambiental. El estudio de Camila Torralbo ofrece una aplicación empírica de la teoría de la aceleración social, del sociólogo alemán Hartmut Rosa, para preguntarse por las dinámicas de politización-despolitización vinculadas a la aprobación de proyectos energéticos. Por su parte, la propuesta de Miguel Schlack aborda el desafío que se le presenta a los gobiernos locales para incorporar en su actuar la inminencia del cambio climático y los efectos en sus territorios.

Con una profunda sensibilidad investigativa, Alice Poma nos propone dos casos de estudios en 
México para observar el rol de las emociones en la defensa del medio ambiente. El apego al lugar, los compromisos afectivos y los valores morales permiten explicar, desde una perspectiva cualitativa, la defensa del medio ambiente. De modo similar, Antonia Zambra y Evelyn Arriagada nos invitan a observar el rol de las mujeres en los conflictos socioambientales. En el marco de la ecología política feminista y de la investigación acción participativa, las autoras ofrecen luces respecto de las formas de liderazgo centradas en el cuidado de la familia, la comunidad y el territorio, las que aparecen en talleres de formación de mujeres dirigentas en la Región Metropolitana de Santiago, Chile.

Como editores invitados a este número especial de la Revista de Sociología hemos querido transmitir que la reflexión sobre los conflictos socioambientales no está cerrada. Por el contrario, sus posibilidades de investigación son todavía muy amplias, si aceptamos -por ejemplolo que Bourdieu y Wacquant (2005) describieron como "sociología reflexiva", donde los objetos de estudio se construyen en el mismo proceso de investigación.

Sin lugar a dudas, este tipo particular de conflictos seguirá creándose y recreándose aceleradamente durante las próximas décadas, entre otras razones porque la posibilidad de limitar el calentamiento global a menos de 1,5 grados (Intergovernmental Panel on Climate Change [IPCC], 2018) resulta cada vez más improbable, por no decir imposible. Si es verdad que durante las próximas décadas viviremos en un planeta más contaminado, donde los océanos se vuelven más ácidos, existe menos agua dulce disponible para el consumo humano y los ecosistemas, aumenta la deforestación y por lo tanto, la temperatura planetaria se incrementa (Rockstrom et. al., 2009) con los efectos extremos en términos de precipitaciones, inundaciones y aluviones que ya conocemos. En este mundo que nos tocará vivir, ¿pueden las ciencias sociales permanecer inalterables? Y, de no serlo así, ¿cuál será nuestro aporte en esta transformación?

\section{REFERENCIAS}

Alimonda, H., Toro Pérez, C., \& Martín, F. (2017). Ecología política latinoamericana. Pensamiento crítico, diferencia latinoamericana y rearticulación epistémica. Buenos Aires, Argentina: CLACSOUniversidad Autónoma Metropolitana.

Bourdieu, P., \& Wacquant, L. (2005). Una invitación a la sociología reflexiva. México: Siglo XXI.

Intergovernmental Panel on Climate Change. (2018). Global warming of $1,5^{\circ}$. Suiza: WMO \& UNEP.
Moore, J. W. (2016). Anthropocene or capitalocene? Nature, history, and the crisis of capitalism. Oakland, CA: PM Press.

Nixon, R. (2013). Slow violence and the environmentalism of the poor. Cambridge, MA: Harvard University Press.

Rockström, J., Steffen, W. L., Noone, K., Persson, Å., Chapin, F. S. III, Lambin, E., ... Nykvist, B. (2009). Planetary boundaries: Exploring the safe operating space for humanity. Ecology and Society, 14(2), 1-3. 